\title{
Erratum to: Morphological changes of injected calcium phosphate cement in osteoporotic compressed vertebral bodies
}

\author{
D. H. Heo • Y. J. Cho • S. H. Sheen • S. U. Kuh • \\ S. M. Cho $\cdot$ S. M. Oh
}

Published online: 4 March 2010

(C) International Osteoporosis Foundation and National Osteoporosis Foundation 2010

\section{Erratum to: Osteoporos Int}

DOI 10.1007/s00198-009-0911-4

In Table 1, the data on "Location of compression fracture" should read: 1 (T8); 1(T11); 2(T12); 4 (L1); 4 (L2); 1 (L4); 1 (L5)

In the subsection "Clinical and radiological analysis", the first sentence of the second paragraph should read: "In addition, we also reviewed many radiological parameters such as the compression ratio, morphological changes of the injected $\mathrm{CaP}$ cement in the vertebral bodies, and the incidence of any subsequent adjacent or remote vertebral compression fractures."
Table 1 Characteristics of patients

\begin{tabular}{ll}
\hline Characteristics & Value \\
\hline Age (year) & $69.42 \pm 10.26$ \\
Sex (M/F) & $4 / 10$ \\
Bone mineral density (T score) & $-3.19 \pm 0.66$. \\
Filler material volume (mL) & $3.98 \pm 0.88$ \\
Mean follow-up period (month) & $25.43 \pm 1.91(24-30$ months) \\
Location of compression fracture & 1 (T8); 1 (T11); \\
& 2 (T12); 4 (L1); 4 (L2); 1 (L4); \\
& 1 (L5) \\
Morphological changes of injected & Seven of 14 patients (50\%) \\
CaP (number of patients) & Reabsorption (6) Osteogenesis \\
& $(2)$ Condensation (2) Bone \\
& cement fracture (1) Heterotopic \\
Progression of compression of & 11 of 14 patients (78.6\%) \\
treated vertebrae & \\
\hline
\end{tabular}

The online version of the original article can be found at http://dx.doi. org/10.1007/s00198-009-0911-4.

D. H. Heo · Y. J. Cho $(\bowtie) \cdot S$. H. Sheen · S. M. Cho · S. M. Oh Department of Neurosurgery, Chuncheon Sacred Heart Hospital, College of Medicine, Hallym University,

153 Kyo-dong, Chuncheon,

Kangwon-do, South Korea

e-mail: nssur771@hallym.or.kr

S. U. Kuh

Department of Neurosurgery, Spine, and Spinal Cord Institute,

Yonsei University College of Medicine,

Seoul, South Korea 